\title{
Engaging Students in Meaningful Learning: Understanding Student Perspectives of Engineering Design Education
}

\author{
Richard J. Aleong, M.A.Sc. Candidate; David S. Strong, Professor \& NSERC Chair in Design Engineering \\ Faculty of Engineering and Applied Science, Queen's University, Ontario, Canada \\ aleongr@ appsci.queensu.ca; strongd@ appsci.queensu.ca
}

\begin{abstract}
Learning how to design plays a vital role in engineering education to prepare students to solve openended, complex problems. To serve the continuous improvement of engineering design education, a qualitative study of undergraduate engineering students' perspectives of engineering design was conducted. This research aims to understand the meaning students place on design in their engineering education and how this meaning is described. By examining what students think about learning and practicing design, engineering educators can be better positioned to enhance instructional strategies and curriculum development. The full extent of the research findings and implications will be presented in the researcher's master's thesis. This paper serves to highlight the application of qualitative research and the learning sciences in engineering education.
\end{abstract}

Keywords: design cognition, engineering pedagogy, learning sciences, qualitative research, student perspectives

\section{INTRODUCTION}

Engineering design holds timely significance for the future of engineering education. Contemporary research literature identifies the need for design education to prepare holistic engineers with the knowledge, skills, and attitudes to innovate and compete globally. To meet the interests from industry and academia, and to enhance the development of future engineering students, it is important to advance the teaching and learning of engineering design. To this end, this paper asks the question: how can engineering educators create meaningful learning experiences for students' learning engineering design?

This current paper builds off of the foundational work first presented at CEEA 2011 [1]. A complimentary paper discussing a preliminary analysis of the research data has also been accepted for publication at the American Society of Engineering Education Annual Conference 2012 [2].

\subsection{Purpose of Research}

This research is focused on investigating students' conceptions on the topic of engineering design. The overarching research question guiding this study is "What meaning do students assign to design within their engineering education"? To unpack this question further, the sub-question was asked: How do undergraduate engineering students' think about learning and practicing design?

Under this sub-question, three topics were identified as the areas of thinking to be explored:

1. What are students' conceptions of design?

2. How do students describe the meaning of design?

3. How do students learn design?

With this framework, the purpose of this research is to explore the conceptions and relationships found in an engineering students' understanding of design thinking.

\subsection{Implications of Research}

This research has implications to build engineering educators' pedagogical content knowledge, defined by Shulman [3] as "the ways of representing and formulating the subject that make it comprehensible to others". Because each student brings different backgrounds and experiences to the classroom, all contributing to what the individual student may already know about the subject, "teachers need knowledge of the strategies most likely to be frutiful in reorganizing the understanding of learners". Shulman stated that "pedagogical content knowledge also includes an understanding of what makes the learning of specific topics easy or difficult". With the knowledge of how students' think about engineering design, engineering educators can build their pedagogical content knowledge and optimize teaching strategies. As Dunsmore, Turns, and Yellin [4] suggested, understanding engineering students' constructions of the engineering profession "could generate leverage points to foster more effective student understandings of engineering practice". 


\subsection{Methodology}

The research methodology in this study is grounded in qualitative inquiry. Qualitative research is "a means of exploring and understanding the meaning individuals or groups ascribe to a social or human problem" [5]. Qualitative inquiry is used to deeply understand the ways engineering students' think about learning and practicing engineering design. A qualitative approach is appropriate for this work because this research serves as an exploration of ways to connect with students in their learning.

A constructivist research paradigm has been adopted that holds the view "that reality is socially constructed" [6]. This research does not seek to find "an objective reality that can be known" but seeks "to understand the multiple social constructions of meaning and knowledge" [6]. It is appropriate to adopt a constructivist view because the research specifically looks at how students construct meaning and knowledge of engineering design. In line with this research paradigm, an interpretivist approach is used to "understand and to portray the participants' perceptions and understandings of the particular situation or event" [7].

\section{RESEARCH DESIGN}

\subsection{Theoretical Constructs}

Theoretical constructs are used to express attributes or characteristics in an abstract, general way. To develop theoretical constructs to frame the research purpose, the overarching research question: "what meaning do engineering students assign to design in their engineering education" was considered. But what does the word "meaning" actually mean, in this context? To explore this topic further the following three questions are offered:

1. What is "understanding"?

2. What is "meaning"?

3. What is "learning"?

\section{What is "understanding"?}

Pask [8] offers this explanation to answer the question 'what is understanding?': "An understanding involves not only the topics that are related and their relationship, but the ability to transfer and apply the relationship to new situations". As Mayer [9] points out, "students understand when they build connections between the new knowledge to be gained and their prior knowledge". Therefore, it is clear that students develop an understanding when the subject matter has meaning.

\section{What is "meaning"?}

Dewey [10] offers this explanation to answer the question 'what is meaning?': “To grasp meaning of a thing, an event, or a situation is to see it in its relations to other things: to note how it operates or functions, what consequences follow from it, what causes it, what uses it can be put to". Therefore, to gain understanding and meaning is to see something in context.

What is "learning"?

The ultimate goal in engineering education and this research is to improve students' learning experiences. Ambrose, Bridges, DiPietro, Lovett, and Norman [11] defined learning "as a process that leads to change, which occurs as a result of experience and increases the potential for improved performance and future learning. Mayer [9] also states that learning includes "not only acquiring knowledge but also being able to use knowledge in a variety of new situations".

These definitions have provided a framework to think about understanding, meaning and learning. Bringing these three concepts together, this research is aimed at fostering meaningful learning: "when students build the knowledge and cognitive processes needed for successful problem solving" [9]. These three concepts have been used as the theoretical constructs to build the measurement instruments and as a way to frame the analytical process of the research.

\subsection{Methods}

A one-time online questionnaire was distributed to first, third, and fourth year undergraduate engineering students at three Canadian Universities. With the exception of first year students, second year students were not targeted as it was desirable to have participants with at least two years of formal engineering education. First year students were included to broaden the variability of participant experiences, as it was assumed that these students represented participants with no formal engineering education. Follow-up semi-structured personal interviews were conducted with interested participants from each of the participating institutions. The questionnaire and interview protocol were designed with questions corresponding to one of the three targeted research constructs presented in Section 1.1 Purpose of Research. The questions were intended to elicit students' descriptions of their experience with practicing and learning engineering design. Students were asked to reflect on their experiences and describe what engineering means to them. 


\section{ANALYSIS}

With qualitative research, the value of the research results comes from the researcher's analysis and interpretation of the data. The purpose of analysis in qualitative research is to draw a conceptual understanding and make meaning out of participant data. To achieve this objective, opening-coding analysis was performed on the responses from the questionnaire and interview transcripts using NVivo ${ }^{\mathrm{TM}}$ software to facilitate the coding process. This open-coding process served to capture the specifics and nuances of the student descriptions. Once codes were generated, these codes were organized into categories and themes of meaning. Multiple iterations of analysis were conducted to consider the interdependencies and interrelationships of the categories.

\section{RESEARCH FINDINGS}

This research provides a way of thinking about the teaching and learning of engineering design and how to engage students in their learning. The research findings are structured into two parts: 1) Students' Understanding of Engineering Design and 2) The Teaching and Learning of Engineering Design. These two parts represent the two orientations taken to approach the research. The first is a student-centered orientation that looks at how students organize their knowledge in terms of understanding. The second part adopts a curriculum orientation that considers the design of holistic curriculum. The full extent of the research findings will be presented in the researcher's master's thesis. The over-arching structure of the research findings is presented here to challenge readers to think about their teaching practice.

\subsection{Students' Understanding of Engineering Design (Student Orientation)}

Students' understanding of engineering design is presented within three structural categories referred to as awareness, relevance, and transfer, corresponding to ways of understanding described in theoretical constructs section of this paper.

Awareness

Engineering students' awareness of engineering design is characterized by their descriptions of what engineering design is about and the conditions in which engineering design takes place.

Relevance

This theme is characterized by how students' describe the relevance of engineering design. Furthermore, this section presents categories that describe how students make connections, relationships, and meaning between engineering design and their other learning.

\section{Transfer}

This theme is characterized by how students describe their experiences of transferring their learning of engineering design to other contexts and how they have used their understanding to solve problems. This section is also defined by elements that are not unique to engineering as a profession, but show students' learning that serve their holistic development as individuals.

\subsection{Teaching and Learning of Engineering Design (Curriculum Orientation)}

Students' perspectives related to the teaching and learning of engineering design were categorized under the three elements of curriculum: subject matter, society, and individual [12]. The design of holistic engineering education requires that these three elements be in balance. Subject Matter

This theme is concerned about teaching the subject matter of engineering design. It captures elements for engineering educators to be mindful of when creating learning experiences and engineering design curriculums. Society

A societal curriculum orientation considers how the school is preparing students to operate in the current society and in an uncertain future. Students' responses that capture societal connections related to the teaching and learning of engineering design are presented under this theme.

Individual

This theme is characterized by the individual element of curriculum that considers how the curriculum serves an individual student's learning needs and interests. The categories that make up this theme consist of elements related to the individual experiences of students.

\section{DISCUSSION}

This research presents a framework for thinking about teaching and learning of engineering design grounded in the learning sciences from educational psychology and based on the conceptual analysis of engineering students' perspectives. The research findings are constructed into three elements of students' understanding referred to as awareness, relevance, and transfer. For learning to be meaningful, students must engage in all three elements. This research has also provided insight for engineering educators to think about their own teaching practice and curriculum development that considers the three elements of holistic curriculum design. In the following discussion sections, two topics that emerged from the research are presented to engage readers in thinking about their role in engineering education. 


\subsection{Designing for the Individual}

The three elements of education that make up an educational experience are students, teachers, and curriculum. To create high quality learning experiences, educators can control for their own behaviour and they have a direct influence over the planned and enacted curriculum. However, controlling for the student becomes complicated because there are many external factors that affect how students learn. As teachers, we can only create an environment that fosters learning. We cannot impose learning onto others, but we can facilitate and direct students through their own journey of learning. Therefore, can we provide the resources for students to become better engineering learners? That is, through our teaching and curriculum, can we prepare students to be learners of the engineering discipline? This study has considered how engineering educators can design curriculum and learning experiences; but what would a design of our students look like, to prepare them to learn engineering? Engineering educators can create opportunities for learning, but for these opportunities to be effective in producing high quality learning, the learner must also be receptive and take responsibility as an active participant in the learning process. Therefore, in parallel to the design of engineering education, how can educators design engineering students to be effective engineering learners?

\subsection{Learning to Design, Learning through Design}

While students participate in engineering design activities, a simultaneous process of 'learning to design' and 'learning through design' is occurring. Engineering students indeed learn how to design, in that they learn the process and tools of design. Students also experience 'learning through design,' characterized by the learning of other knowledge and skills, that may or may not be directly related to technical engineering itself. 'Learning through design' uses the process of designing as the medium for other learning. For example, because students are designing in a multidisciplinary team, they are learning and practicing teamwork skills, although teamwork skills may not be the direct objective for doing the design project.

Design projects offer rich learning experiences for students through various pedagogical characteristics as shown in Figure 1.

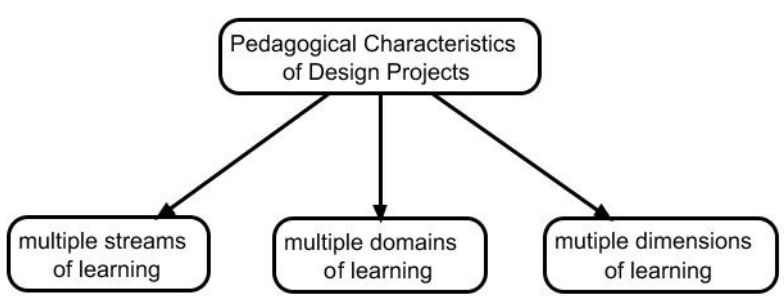

Figure 1: Design projects offer multiple streams of learning, levels of learning, and dimensions of learning.

It is proposed that design projects provide multiple streams of learning with the advantage of learning in multiple learning domains. In this context, "streams of learning" are the ways students can learn. Design projects provide opportunities to learn individually or in a team, to conduct research through reading or through experiments, to work at a desk or in the field. The different learning domains are referred to as cognitive, affective, and psychomotor, to describe the extent of knowledge, attitudes, and skills that are developed through design projects. As one student said, "design projects are the time when I can bring together knowledge from other areas." Finally, design projects are multidimensional in relation to the three elements of curriculum. Design projects allow for the integration of learning across subject matter, society, and the individual.

The pedagogical characteristics of design projects afford the opportunity for students to learn to design and through design. This model is provided as a conceptual framework for thinking about the design project experience. With this understanding, engineering educators can help students optimize the value of the design experience.

\section{CONCLUSION AND RECOMMENDATIONS}

This paper has highlighted two emerging techniques in engineering education research: qualitative research methodology and the application of the learning sciences to design instruction. With an understanding of how students learn and think about design, engineering educators may be better prepared to optimize curriculum development and instructional practice. Recommendations for teaching practice and further research are provided below:

Recommendation \#1: To engage students in meaningful learning, engineering educators must consider how their teaching methods promote students' learning on all three levels of understanding: awareness, relevance, and transfer.

Recommendation \#2: To engage students in meaningful learning, engineering educators must consider how their teaching practice serves the holistic curriculum of subject matter, society, and the individual. 
Recommendation \#3: Recognizing that knowledge and understanding is socially constructed, future avenues for this research include focus groups or observational activities to see how engineering students negotiate meaning with their peers. Other opportunities to understand students' constructions of engineering knowledge should be pursued to validate these research findings and provide further insight to the design of engineering education. Furthermore, studies of Faculty perspectives on engineering design should be conducted to highlight potential issues of alignment between student and teacher perspectives that may pose challenges to the implementation of the research findings.

\section{Acknowledgements}

The authors would like to acknowledge funding from the NSERC Chairs in Design Engineering program for making this research possible. The authors wish to thank the many staff at the participating institutions who distributed the research questionnaire and the students for their participation. Special thanks are extended to Dr. Ralph Buchal and Dr. Amarjeet Bassi at the University of Western Ontario and Dr. Susan McCahan at the University of Toronto for their support.

\section{References}

[1] Aleong, R.J., \& Strong, D.S. (2011, June). A qualitative study of undergraduate engineering students, understanding of design - A work in progress. Paper presented at the Canadian Engineering Education Association Annual Conference, St. John's, Newfoundland.
[2] Aleong, R.J., \& Strong, D.S. (2012, June). Student perspectives of engineering design education. Paper accepted for publication at the American Society of Engineering Education Annual Conference 2012, San Antonio, Texas.

[3] Shulman, L.S. (1986). Those who understand: Knowledge growth in teaching. Educational Researcher, 15(2), 4-14.

[4] Dunsmore, K., Turns, J., Yellin, J.M. (2011). Looking toward the real world: Student conceptions of engineering. Journal of Engineering Education, 100(2), 329-348.

[5] Creswell, J.W. (2009). Research design: Qualitative, quantitative, and mixed methods approaches. Thousand Oaks, CA: Sage

[6] Mertens, D.M. (2005). Research and evaluation in education and psychology. Thousand Oaks, CA: Sage.

[7] Bartlett, S., Burton, D. (2007). Introduction to education studies. Thousand Oaks, CA: Sage

[8] Pask, G. (1998). Learning strategies, teaching strategies, and conceptual or learning style. In R.R. Schmeck (Ed.), Learning strategies and learning styles (pp. 83-100). New York, NY: Plenum Press.

[9] Mayer, R.E. (2002). Rote versus meaningful learning. Theory Into Practice. 41(4), 226-232

[10] Dewey, J. (1933). How we think. Boston: D.C. Heath and Company.

[11] Ambrose, S. A., Bridges, M., DiPietro, M., Lovett, M., \& Norman, M. (2010). How learning works. San Francisco: Jossey Bass.

[12] Marsh, C., \& Willis, G. (2007). Curriculum: Alternative approaches, ongoing issues. New Jersey: Pearson Education. 